\title{
Analysis of the Relevance Between Water Resources Utilization and Industrial Development in Beijing
}

\author{
Dan $\mathrm{Wu}^{1, *}$ Renxing Yang ${ }^{1}$ Yue $\mathrm{Li}^{1}$ Yanlai Jin ${ }^{1}$ \\ ${ }^{1}$ School of Economics and Management, North China University of Technology, Beijing 100144, China \\ *Corresponding author.Email: wu_daniel@163.com
}

\begin{abstract}
The authors analyze the evolution of Beijing's water resources utilization based on changes in Beijing's industrial water use, adjustment of water structure and changes in water efficiency. At the same time, combined with changes in Beijing's economic and industrial development, the authors use the method of industrial structure change coefficient to reveal the direction of Beijing's industrial structure change. On this basis, the grey correlation evaluation method is used to measure the correlation between water resources utilization and industrial structure in Beijing. And the Tapio elasticity coefficient method is used to determine the water elasticity coefficient for the three industries in Beijing. Studies have shown that during the "Eighth Five-Year Plan" to "Thirteenth Five-Year Plan" period, Beijing's industrial and agricultural water consumption has fallen rapidly, and domestic water consumption has risen rapidly, changing from the largest proportion of agricultural water to the largest proportion of domestic water. The average value of the change coefficient of the primary and secondary industry structure in Beijing is always negative, and the average value of the change coefficient of the tertiary industry structure is always positive. The tertiary industry is showing a relatively stable expansion trend. Beijing's primary industry has the highest correlation with water resources utilization, followed by the secondary industry, and the tertiary industry is the lowest. The correlation between the three industries in Beijing and the utilization of water resources has shown a gradual decline. The water elasticity coefficients of the primary and secondary industries are generally negative, and the water elasticity coefficients of the tertiary industry are always positive.
\end{abstract}

Keywords: Beijing, Water resources, Industrial structure, Relevance, Elasticity coefficient.

\section{INTRODUCTION}

Water resources are a strategic resource for the sustainable development of Beijing's economy and

*Project: 2021 Beijing University Students' Innovation and Entrepreneurship Training Program "Research on the Coordination Evaluation of Beijing's Economic Development and Water Resources Utilization" (Grant No.: 108051360021XN216/004); Project of Beijing Undergraduate Innovation and Entrepreneurship Training Program in 2021, "Research on Coordination Evaluation of Economic Development and Water Resources Utilization in Beijing" (Grant No.: 108051360021XN216/004); The Yuyou Talent Project of North China University of Technology "Research on the Evaluation System of Beijing-Tianjin-Hebei Resource and Energy Management Performance and Collaborative Governance Capability from the Perspective of Technological Innovation" (Grant No.: 107051360021XN083/055); The general project of Beijing Municipal Natural Science Foundation of China "Research on the Bidirectional Optimal Adaptation of Water Resources and Industrial Structure Under the Coordinated Development of Beijing-Tianjin-Hebei Region" (Grant No.: 9202005). society, providing an important guarantee for economic and industrial development, residents' lives, and environmental protection. At present, on the basis of analyzing the evolution of water resources characteristics such as the amount of water resources and water supply structure in Beijing [1], [2], [3], [4], [5], [6], [7], scholars have reasonably predicted the water demand of Beijing's economic and social development [8], [9], [10], carried out an analysis of the correlation between water resources utilization and economic development, and determined the temporal and spatial changes of Beijing's industrial water use and influencing factors[11], [12], [13], [14], [15]. Scholars have also focused on evaluating the decoupling relationship between water resource utilization efficiency, water resource utilization and economic development in Beijing [16], [17], [18], [19], [20], [21]. However, few scholars have 
adopted long-term sequences to analyze the correlation between water resources utilization and industrial development in Beijing during different planning periods. To this end, the industrial structure change coefficient method, the gray correlation evaluation method and the Tapio elastic coefficient method are used to study the correlation between Beijing's water resources and the industrial structure in different planning periods, and the water elasticity coefficient of Beijing's three industries.

\section{THE EVOLUTION OF WATER RESOURCES UTILIZATION AND INDUSTRIAL STRUCTURE IN BEIJING}

\subsection{The Evolution of Water Resources Utilization}

During the period from the "Eighth Five-Year Plan" to the "Thirteenth Five-Year Plan" period, the average value of Beijing's total water consumption showed a fluctuating downward trend, from 4.418 billion cubic meters to 3.983 billion cubic meters, as shown in "Table 1".

Table 1. Beijing water resources utilization changes during "the Eighth Five-Year Plan" to "the Thirteenth FiveYear Plan" period

\begin{tabular}{|c|c|c|c|c|}
\hline \multirow{2}{*}{ Planning period } & $\begin{array}{l}\text { Total water } \\
\text { consumption }\end{array}$ & $\begin{array}{l}\text { Agricultural water } \\
\text { consumption }\end{array}$ & $\begin{array}{l}\text { Industrial water } \\
\text { consumption }\end{array}$ & $\begin{array}{l}\text { Domestic water } \\
\text { consumption }\end{array}$ \\
\hline & Mean value $/ m^{3}$ & Mean value $/ m^{3}$ & Mean value $/ m^{3}$ & Mean value $/ m^{3}$ \\
\hline The 9th Five-Year Plan & 40.76 & 18 & 10.96 & 11.8 \\
\hline The 11th Five-Year Plan & 34.98 & 11.47 & 5.48 & 15 \\
\hline The 12th Five-Year Plan & 36.78 & 8.64 & 4.78 & 16.6 \\
\hline The 13th Five-Year Plan & 39.83 & 4.75 & 3.48 & 18.30 \\
\hline
\end{tabular}

According to "Table 1", during the "Eighth Five-Year Plan" to "Thirteenth Five-Year Plan" period, the mean value of agricultural water consumption declined rapidly, from 2.087 billion cubic meters to 475 million cubic meters, a decrease of more than $75 \%$. The mean value of industrial water consumption dropped rapidly, from 1.377 billion cubic meters to 348 million cubic meters, a decrease of $75 \%$. The mean value of domestic water consumption increased rapidly, from 955 million cubic meters to 1.830 billion cubic meters, an increase of nearly double. Among them, domestic water takes the first place in the water structure, followed by ecological water, and agricultural water takes the third place in the water structure. The adjustments of Beijing's water consumption structure and changes in water efficiency during "the Eighth Five-Year Plan" to "the Thirteenth Five-Year Plan" period are shown in "Table 2". 
Table 2. Beijing's water structure adjustment and water efficiency changes during "the Eighth Five-Year Plan" to "the Thirteenth Five-Year Plan" period

\begin{tabular}{|c|c|c|c|c|c|c|c|c|}
\hline \multirow{2}{*}{$\begin{array}{l}\text { Planning } \\
\text { period }\end{array}$} & \multicolumn{3}{|c|}{$\begin{array}{c}\text { Percentage of water consumption } \\
\text { structure } \%\end{array}$} & \multicolumn{3}{|c|}{$\begin{array}{l}\text { Changes in water consumption } \\
\text { growth/100 million cubic meters }\end{array}$} & \multicolumn{2}{|c|}{$\begin{array}{l}\text { Water use efficiency } \\
\text { change index }\end{array}$} \\
\hline & Agriculture & Industry & Living & Agriculture & Industry & Living & Agriculture & Industry \\
\hline $\begin{array}{l}\text { The 8th } \\
\text { Five-Year } \\
\text { Plan }\end{array}$ & 47.34 & 31.11 & 21.54 & -2.41 & 1.44 & 4.73 & 0.53 & 0.46 \\
\hline $\begin{array}{l}\text { The 9th } \\
\text { Five-Year } \\
\text { Plan }\end{array}$ & 44.15 & 26.90 & 28.95 & -2.84 & -3.26 & 1.62 & 0.79 & 0.48 \\
\hline $\begin{array}{l}\text { The 10th } \\
\text { Five-Year } \\
\text { Plan }\end{array}$ & 40.13 & 21.81 & 35.70 & -3.82 & -3.72 & 0.54 & 0.69 & 0.32 \\
\hline $\begin{array}{l}\text { The 11th } \\
\text { Five-Year } \\
\text { Plan }\end{array}$ & 32.80 & 15.69 & 42.87 & -1.84 & -1.74 & 1.37 & 0.61 & 0.46 \\
\hline $\begin{array}{l}\text { The 12th } \\
\text { Five-Year } \\
\text { Plan }\end{array}$ & 23.57 & 13.03 & 45.13 & -4.43 & -1.26 & 2.20 & 0.52 & 0.56 \\
\hline $\begin{array}{l}\text { The 13th } \\
\text { Five-Year } \\
\text { Plan }\end{array}$ & 11.98 & 8.74 & 45.97 & -2.70 & -0.50 & 1.20 & 0.71 & 0.76 \\
\hline
\end{tabular}

According to "Table 2", during the "Eighth Five-Year Plan" to "Thirteenth Five-Year Plan" period, first, from the perspective of industrial water use structure adjustment, the proportion of industrial and agricultural water structure continued to decline, and the proportion of domestic water structure continued to rise. By the "Thirteenth FiveYear Plan" period, the changes in the average proportions of agricultural, industrial, and domestic water consumption structures were $-35.36 \%$, $22.37 \%$, and $24.43 \%$, respectively, changing from the largest average proportion of agricultural water consumption $(47.34 \%)$ to the largest average proportion of domestic water consumption $(45.97 \%)$. Second, from the perspective of changes in industrial water consumption and water efficiency, both industrial and agricultural water consumption has a negative growth (only industrial water consumption during the "the Eighth FiveYear Plan" period), and the growth trend of domestic water consumption is an overall decline, from 473 million cubic meters to 120 million cubic meters. The industrial and agricultural water use efficiency change index is always less than 1 , and the industrial and agricultural water use efficiency continues to improve, but the improvement space is gradually shrinking.

\subsection{The Evolution Trend of Industrial Structure}

The economic scale of Beijing has grown substantially, the economic growth rate has continued to decline, the service industry has developed rapidly, and the industrial structure has formed a "three-two-one" pattern, which has risen to the level of developed countries. During "the Eighth Five-Year Plan" to "the Thirteenth FiveYear Plan" period, with the acceleration of Beijing's industrialization process, Beijing has accelerated the adjustment and transformation of its industrial structure. The proportion of the primary industry and the secondary industry's structure has steadily declined, and the proportion of the tertiary industry's structure has risen rapidly. Beijing's economic development has entered a post-industrial period, with the tertiary industry dominating. Among them, the average proportion of the primary industry and the secondary industry structure dropped from $6.28 \%$ and $46.57 \%$ to $0.38 \%$ and $17.36 \%$ respectively, and the average proportion of the tertiary industry structure rose from $47.16 \%$ to $82.25 \%$ (see "Figure 1"). 


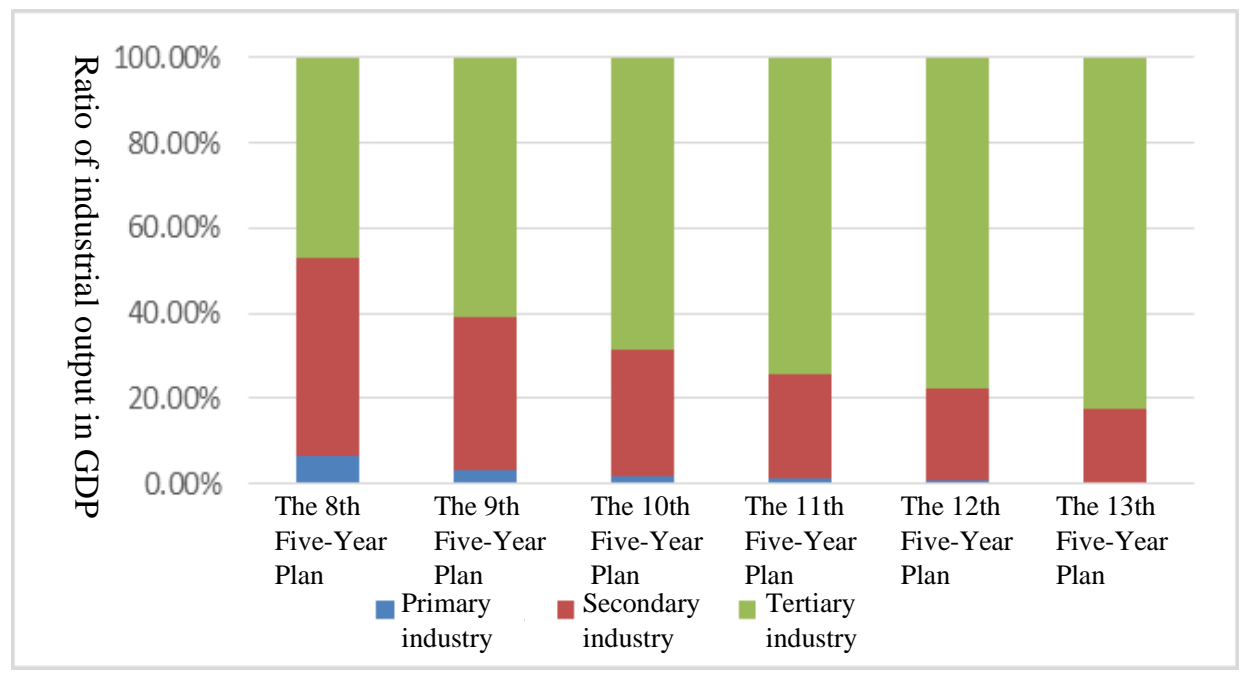

Figure 1 Trends of Beijing's industrial structure during "the Eighth Five-Year Plan" to "the Thirteenth Five-Year Plan" period.

According to "Figure 1", the coefficient of change in Beijing's industrial structure during "the Eighth Five-Year Plan" to "the Thirteenth FiveYear Plan" period can be further measured. The coefficient of industrial structure change is mainly to reveal the direction of industrial structure change through the comparison of the proportion of the current output value of the three industries and the proportion of the base period output value. From the perspective of the change coefficient of Beijing's industrial structure, first, during the period from "the Eighth Five-Year Plan" to "the Thirteenth Five-Year Plan", the mean value of the change coefficient of Beijing's primary industry structure was always negative, and the primary industry showed a rapid contraction. Among them, during the period from "the Eighth Five-Year Plan" to "the Tenth Five-Year Plan", the absolute value of the mean value of the coefficient of variation of the primary industry reached more than $10 \%$. During the period from "the Eleventh Five-Year Plan" to "the Twelfth Five-Year Plan", the absolute value of the mean value of the coefficient of variation of the primary industry was close to $7 \%$. By "the thirteenth Five-Year Plan" period, the absolute value of the mean value of the coefficient of variation of the primary industry exceeded $13 \%$. Second, during the period from "the Eighth FiveYear Plan" to "the Thirteenth Five-Year Plan" period, the mean value of the coefficient of variation of Beijing's secondary industry structure was always negative, and the secondary industry showed a gradual contraction trend. The absolute value of the mean value of the coefficient of variation of the secondary industry fluctuatedly increased from $3.92 \%$ to $4.21 \%$. Third, during the period from "the Eighth Five-Year Plan" to "the Thirteenth Five-Year Plan" period, the mean value of the coefficient of variation of Beijing's tertiary industry structure was always positive, and the tertiary industry showed a relatively stable expansion trend. However, the mean value of the coefficient of variation of the tertiary industry structure continued to drop from $6.18 \%$ to $1.04 \%$ during "the Thirteenth Five-Year Plan" period (see "Figure 2"). 


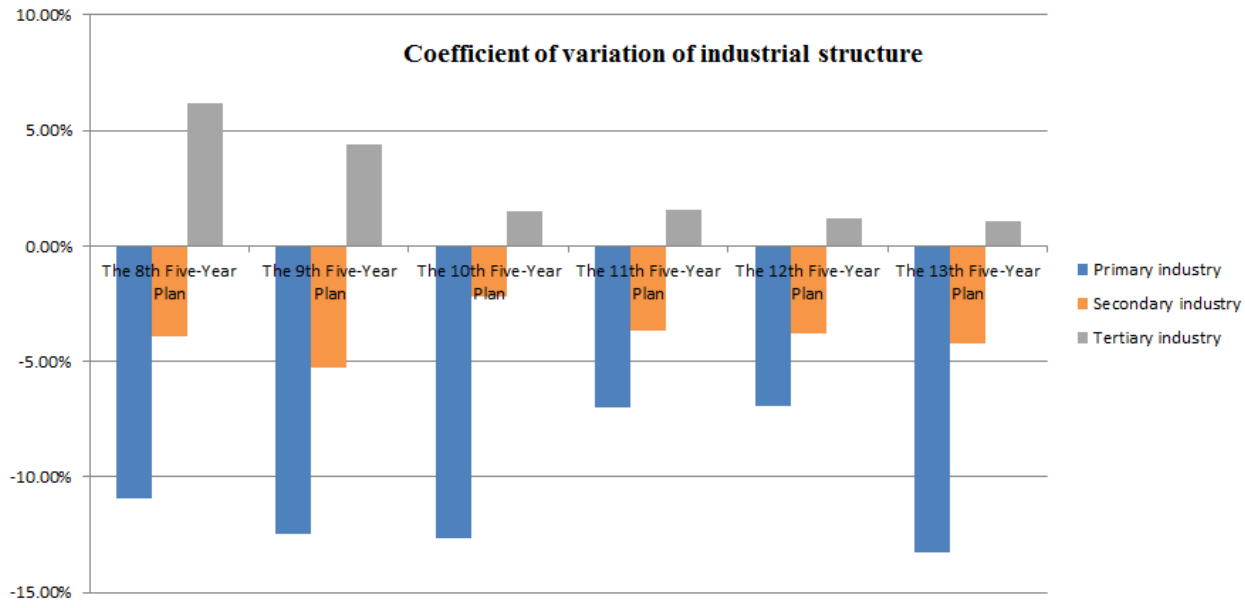

Figure 2 The coefficient of variation of Beijing's industrial structure during "the Eighth Five-Year Plan" to "the Thirteenth Five-Year Plan" period.

\section{CALCULATION OF CORRELATION BETWEEN WATER RESOURCES UTILIZATION AND INDUSTRIAL STRUCTURE IN BEIJING}

According to the evolution of Beijing's water resources utilization and industrial structure in different periods, the grey relational evaluation method is used to measure the correlation between Beijing's water resources and industrial structure.

$$
\left\{\begin{array}{l}
C_{k}=\frac{1}{T} \sum_{t=1}^{T} N_{k}(t) \\
N_{k}(t)=\frac{\left[\min _{k} \min _{t}\left|Y^{\prime}(t)-X_{k}^{\prime}(t)\right|+\rho \max _{k} \max _{t}\left|Y^{\prime}(t)-X_{k}^{\prime}(t)\right|\right]}{\left|Y^{\prime}(t)-X_{k}^{\prime}(t)\right|+\rho \max _{k} \max _{t}\left|Y^{\prime}(t)-X_{k}^{\prime}(t)\right|} \\
Y^{\prime}(t)=\frac{Y(t)}{Y\left(t_{0}\right)} \\
X_{k}^{\prime}(t)=\frac{X_{k}(t)}{X_{k}\left(t_{0}\right)} \\
Y(t)=\{Y(1), Y(2), \cdots, Y(n)\} \\
X_{k}(t)=\left\{X_{k}(1), X_{k}(2), \cdots, X_{k}(n)\right\}
\end{array}\right.
$$

In formula (1), the $C_{k}$ is the correlation between Beijing's $k$ industry and the utilization of water resources $(k=1,2,3$ represents the primary industry, the secondary industry, and the tertiary industry respectively). The $N_{k}(t)$ is the gray correlation coefficient of the water resources utilization and the $k$ industry during the period of
Taking Beijing's water resource utilization in different periods as the parent variable and Beijing's industrial structure in different periods as the subvariables, the water resources utilization variables and industrial structure variables of Beijing are processed in a dimensionless manner to determine Beijing's water resource utilization and industrial structure. The degree of relevance between can be expressed as $t Y^{\prime}(t)$ and $X_{k}^{\prime}(t)$ are the dimensionless values of $Y(t)$ and $X_{k}(t)$ respectively. $Y(t)$ and $Y\left(t_{0}\right)$ are respectively the water resources utilization in the period of $t$ and the base period $t_{0}$ period. $X_{k}(t)$ and $X_{k}\left(t_{0}\right)$ are the economic added value of $k$ industry in the $t$ period and the 
base period $t_{0}$ period. $\rho$ is called the resolution coefficient, and the general value interval is $[0,1]$. The smaller the $\rho$, the greater the resolution, and $\rho=0.5$ is usually used. The $\min _{k} \min _{t}\left|Y^{\prime}(t)-X_{k}^{\prime}(t)\right| \quad$ represents the minimum difference between the two levels, where $\min _{t}\left|Y^{\prime}(t)-X_{k}^{\prime}(t)\right|$ is the minimum difference of the first level, and $\min _{k}\left(\min _{t}\left|Y^{\prime}(t)-X_{k}^{\prime}(t)\right|\right)$ is the minimum difference of the second level; $\max _{k} \max _{t}\left|Y^{\prime}(t)-X_{k}^{\prime}(t)\right|$ represents the maximum difference between the two levels, where $\max _{t}\left|Y^{\prime}(t)-X_{k}^{\prime}(t)\right|$ is the maximum difference of the first level, and $\max _{k}\left(\max _{t}\left|Y^{\prime}(t)-X_{k}^{\prime}(t)\right|\right)$

$$
\max _{k}\left(\max _{t}\left|Y^{\prime}(t)-X_{k}^{\prime}(t)\right|\right)
$$

is the maximum difference of the second level.

According to formula (1), the correlation between water resource utilization and industrial structure in Beijing is calculated, as shown in "Table 3".

Table 3. Correlation degree between Beijing's water resources utilization and industrial structure during the period from "the Eighth Five-Year Plan" to "the Thirteenth Five-Year Plan"

\begin{tabular}{|c|c|c|c|c|c|}
\hline Planning period & $\begin{array}{c}\text { Correlation degree } \\
\text { between primary } \\
\text { industry and water } \\
\text { resources }\end{array}$ & $\begin{array}{c}\text { Correlation degree } \\
\text { between secondary } \\
\text { industry and water } \\
\text { resources }\end{array}$ & $\begin{array}{c}\text { Correlation degree } \\
\text { between tertiary } \\
\text { industry and water } \\
\text { resources }\end{array}$ & $\begin{array}{c}\text { Correlation degree } \\
\text { between agriculture } \\
\text { and water } \\
\text { resources }\end{array}$ & $\begin{array}{c}\text { Correlation degree } \\
\text { between industry } \\
\text { and water } \\
\text { resources }\end{array}$ \\
\hline $\begin{array}{l}\text { The 9th Five-Year } \\
\text { Plan }\end{array}$ & 0.989 & 0.969 & 0.914 & 0.923 & 0.812 \\
\hline $\begin{array}{l}\text { The 11th Five-Year } \\
\text { Plan }\end{array}$ & 0.977 & 0.881 & 0.632 & 0.851 & 0.503 \\
\hline $\begin{array}{l}\text { The 12th Five-Year } \\
\text { Plan }\end{array}$ & 0.966 & 0.822 & 0.478 & 0.786 & 0.384 \\
\hline $\begin{array}{l}\text { The 13th Five-Year } \\
\text { Plan }\end{array}$ & 0.975 & 0.783 & 0.358 & 0.834 & 0.339 \\
\hline
\end{tabular}

According to "Table 3", during "the Eighth Five-Year Plan" to "the Thirteenth Five-Year Plan" period, firstly, from the perspective of the correlation between the three industries in Beijing and the utilization of water resources, the primary industry has the highest correlation with the utilization of water resources, followed by the secondary industry, and the tertiary industry is the lowest. The correlation between the three industries and the utilization of water resources has shown a gradual decline. The mean value of the correlation between primary industry, secondary industry, tertiary industry and water resource utilization decreased from $0.997,0.991,0.982$ to $0.975,0.783$, and 0.358 , respectively. The primary industry is strongly dependent on the use of water resources. Secondly, from the perspective of the correlation between industry and agriculture and water resource utilization in Beijing, the correlation between agriculture and water resource utilization is declining in a fluctuating manner, and industry and water resource utilization are declining rapidly.
The mean value of the correlation between agriculture, industry and water resource utilization decreased from 0.975 and 0.941 to 0.834 and 0.339 , respectively. Agriculture has a strong dependence on the use of water resources. On the whole, from 1990 to 2019 , the mean value of the correlation between the primary industry, the secondary industry, and the tertiary industry and the utilization of water resources was $0.982,0.904$, and 0.716 , respectively. The mean values of the correlation between agriculture, industry and water resource utilization are 0.883 and 0.628 respectively.

\section{MEASUREMENT AND CALCULATION OF BEIJING'S INDUSTRIAL WATER ELASTICITY COEFFICIENT}

Combining the evolution of water resources utilization and industrial structure in Beijing, the Tapio elasticity coefficient method is used to 
measure the water elasticity coefficient of the three industries in Beijing, which can be expressed as

$$
\left\{\begin{array}{l}
T^{t_{1}}=\frac{\Delta W^{t_{1}} / W^{t_{0}}}{\Delta G^{t_{1}} / G^{t_{0}}} \\
T_{j}^{t_{1}}=\frac{\Delta W_{j}^{t_{1}} / W_{j}^{t_{0}}}{\Delta G_{j}^{t_{1}} / G_{j}^{t_{0}}}
\end{array}\right.
$$

In formula (2), $T^{t_{1}}$ represents the water elasticity coefficient of Beijing in the period of $t_{1}$. Among them, $\Delta W^{t_{1}}$ represents the increase in total water consumption in Beijing during the period of $t_{1}$ relative to the period of $t_{0} ; W^{t_{0}}$ represents the total water consumption of Beijing during the period of $t_{0} ; \Delta G^{t_{1}}$ represents the change in the economic output value of Beijing in the period of $t_{1}$ relative to the period of $t_{0} ; G^{t_{0}}$ represents the total economic output value of $i$ region of the BeijingTianjin-Hebei area during $t_{0} \cdot T_{j}^{t_{1}}$ represents the

Table 4. Beijing's three industries water elastic coefficient during the period from "the Eighth Five-Year Plan" to "the Thirteenth Five-Year Plan"

\begin{tabular}{|c|c|c|c|c|}
\hline Planning period & $\begin{array}{l}\text { Total elastic } \\
\text { coefficient of water } \\
\text { consumption }\end{array}$ & $\begin{array}{c}\text { Elastic coefficient of } \\
\text { water consumption of } \\
\text { primary industry }\end{array}$ & $\begin{array}{l}\text { Elastic coefficient of } \\
\text { water consumption of } \\
\text { secondary industry }\end{array}$ & $\begin{array}{l}\text { Elasticity coefficient of } \\
\text { water consumption of } \\
\text { tertiary industry }\end{array}$ \\
\hline The 9th Five-Year Plan & -0.091 & -1.878 & -0.394 & 0.120 \\
\hline The 11th Five-Year Plan & 0.020 & -0.361 & -0.381 & 0.169 \\
\hline The 12th Five-Year Plan & 0.135 & -3.209 & -0.731 & 0.233 \\
\hline The 13th Five-Year Plan & 0.171 & 2.230 & -0.510 & 0.105 \\
\hline
\end{tabular}

According to "Table 4", during the period from "the Eighth Five-Year Plan" to "the Thirteenth Five-Year Plan", the total water consumption in Beijing fluctuated and declined slightly. However, the total elastic coefficient of water consumption is generally positive. Among them, during the period from "the Eighth Five-Year Plan" to "the Twelfth Five-Year Plan", the primary industry's water consumption elasticity coefficient was negative. By "the Thirteenth Five-Year Plan" period, although the water consumption of the primary industry continues to decline, the added value of the primary industry has declined, causing the elasticity of the primary industry to turn positive. During "the Ninth Five-Year Plan" period to "the Thirteenth Five- elastic coefficient of decoupling of $j$ industrial water consumption during the $t_{1}$ period ( $j=1,2,3$ represents the primary industry, the secondary industry, and the tertiary industry). Among them, $\Delta W_{j}^{t_{1}}$ represents the increase in water consumption of $j$ industry during $t_{1}$ period compared to $t_{0}$ period; $W_{j}^{t_{0}}$ represents the water consumption of $j$ industry during $t_{0}$ period; $\Delta G_{j}^{t_{1}}$ represents the change in the economic added value of $j$ industry during $t_{1}$ period relative to $t_{0}$ period; $G_{j}^{t_{0}}$ respectively represents the economic added value of $j$ industry during $t_{0}$ period.

According to formula (2), the water elasticity coefficient of the three industries in Beijing during "the Eighth Five-Year Plan" to "the Thirteenth Five-Year Plan" period is calculated, as shown in "Table 4".
Year Plan" period, the secondary industry's water consumption was effectively controlled, and the secondary industry's water elasticity coefficient was always negative. During "the Eighth Five-Year Plan" period to "the Thirteenth Five-Year Plan" period, the water consumption of the tertiary industry continued to grow, the water elasticity coefficient of the tertiary industry was always positive, and the growth rate of the water consumption of the tertiary industry slowed down.

\section{CONCLUSION}

During "the Eighth Five-Year Plan" to "the Thirteenth Five-Year Plan" period, Beijing's total 
water consumption showed a fluctuating downward trend. Industrial and agricultural water consumption was rapidly declining, and domestic water consumption was rising sharply, changing from the largest proportion of agricultural water to the largest proportion of domestic water. However, the growth and change trend of domestic water consumption is an overall decline, and the efficiency of industrial, agricultural and domestic water use in Beijing has continued to improve. The primary industry has the highest correlation with water resources utilization, followed by the secondary industry, and the tertiary industry is the lowest. The correlation between the three industries and the utilization of water resources has shown a gradual decline. The correlation between agriculture and water resource utilization is declining in a fluctuating manner, and industry and water resource utilization are declining rapidly. The water elasticity coefficients of the primary and secondary industries are generally negative, and the water elasticity coefficients of the tertiary industry are always positive. The direction of Beijing's water resources optimization is to appropriately reduce the use of water resources in the primary and secondary industries and increase the use of water in the tertiary industry under the premise of ensuring the safety of food production. That is, through industrial and agricultural water-saving technologies and other measures, it is important to give priority to controlling the water consumption of the primary industry, strictly controlling the water consumption of the secondary industry, and rationally increasing the water consumption of the tertiary industry, so as to effectively improve the comprehensive output of water resources under the rigid constraints of Beijing's water resources.

\section{AUTHORS' CONTRIBUTIONS}

Dan $\mathrm{Wu}$ is responsible for experimental design and writing the manuscript, Renxing Yang, Yue Li, Yanlai Jin are responsible for analyzing data and writing the manuscript.

\section{REFERENCES}

[1] Liu Yang, Liu Dejun, Qi Xinghui, Analysis of Reclaimed Water Utilization in Beijing Under Water Impact Assessment System [J]. China Water Resources, 2020(17): 45-47. (in Chinese)

[2] Zhang Yajun, Gao Xiaoxia, Wang Jing, etc. Brief Talk on the Water Resources Situation in Beijing and the Measures to Improve the Wastewater Resource Utilization [J]. Energy Conservation and Environment Protection, 2019(05): 38-40. (in Chinese)

[3] Wan Wenhua, Yin Junhan, Zhao Jianshi, etc. Sustainability evaluation of Beijing Water Deployment Model Before and After Southto-North Water Diversion [J]. South-to-North Water Transfers and Water Science \& Technology, 2016, 14(02): 62-69. (in Chinese)

[4] Guan Zhuojin, Ma Zhijie, Huang Lihua, etc. Groundwater Variation Trend Model and Water Balance Analysis in Beijing [J]. China Water Resources, 2016(03): 29-31. (in Chinese)

[5] Zhang Xiuli, Ni Na, Impact of changes of Beijing Extreme Precipitation Events on City Water Resources [J]. Ningxia Journal of Agriculture and Forestry Science and Technology, 2013, 54(02): 103-106. (in Chinese)

[6] Qin Ling, Du Pengfei, Zheng Yu, 2049 Beijing Water Resources Utilization Development Trend and Supply-Demand Balance Research [J]. Beijing City Planning \& Construction Review, 2012(03): 45-49. (in Chinese)

[7] Yun Yi, Zou Zhihong, Wang Huiwen, Analysis on Beijing's Urban Water Resource Demand-Supply System [J]. Mathematics in Practice and Theory, 2011, 41(12): 129-136. (in Chinese)

[8] Zhou Yongjun, Prediction of Water Shortage in Beijing Based on DDEPM Method [J]. Statistics \& Decision, 2015(03): 62-64. (in Chinese)

[9] Shao Huifang, Zhang Tong, Huang Daying, etc. Research on Prediction of Urban Water Demand in Beijing $[\mathrm{J}]$. Beijing Water, 2012(01): 23-27. (in Chinese)

[10] Zhong Chenyu, Hu Huiting, Forecasting and Optimizing of Water Resources Based on Grey Prediction and Multi-objective Planning Model [J]. Journal of Sichuan University of Science \& Engineering: Natural Science Editton, 2013, 26(05): 90-95. (in Chinese)

[11] Wu Dan, Wang Hongji, Liu Shuai, Correlation Analysis of Beijing's Economic Development and Water Resources Consumption and 
Utilization [J]. Collective Economy, 2019(11): 32-33. (in Chinese)

[12] Sun Yanzhi, Lu Chunxia, Xie Gaodi, etc. The Conjunction Between Urban Development and the Utilization of Water Resources in Beijing [J]. Resources Science, 2015, 37(06): 11241132. (in Chinese)

[13] Wu Dan, Correlation Analysis and Bidirectional Optimization Model of Industrial Structure and Water Resources in BeijingTianjin-Hebei Region [J]. China Polulation.Resources and Environment, 2018, 28(09): 158-166. (in Chinese)

[14] Liu Yang, Li Lijuan, The Relationship Between Industrial Structure and Water Consumption Structure in Beijing-TianjinHebei Region [J]. South-to-North Water Transfers and Water Science \& Technology, 2019, 17(02): 1-9. (in Chinese)

[15] Li Qingya, Pei Liang, Sun Liying, etc. Study on Temporal and Spatial Variation and Influencing Factors of Industrial Water Consumption in Beijing-Tianjin-Hebei Region [J]. Ecological Economy, 2020, 36(10): 141145+159. (in Chinese)

[16] Wu Dan, Kang Xue, Evaluation of the Decoupling of Beijing's Economic Development and Water Resources Consumption and Utilization [J]. China Collective Economy, 2019(14): 28-29. (in Chinese)

[17] $\mathrm{Wu}$ Dan, Xu Heyan, Evaluation on the Decoupling Trend and Efficiency of Water Resource Utilization of Economic Development in Beijing $[\mathrm{J}]$. Science Technology and Industry, 2018, 18(11): 3338. (in Chinese)

[18] Yang Jingxue, Hong Chuanchun, Decoupling of Water Resources Utilization and Economic Growth in Beijing-Tianjin-Hebei Region: Based on Water Footprint Method [J]. Economic Vision, 2018(05): 21-29. (in Chinese)

[19] Jiang Boqian, Liu Xin, Evaluation on Efficiency of Water Utilization of Bohal Economic Zone Based on DEA - Malmquist [J]. Resource Development \& Market, 2015, 31(01): 49-51. (in Chinese)
[20] Qiao Hongmin, Li Weiqing, He Zhongwei, Studying on the Beijing Agricultural Utilization of Water Resources [J]. Science Technology and Industry, 2016, 16(07): 1114. (in Chinese)

[21] Chang Jing, Jia Yucheng, Analysis on Coordination Degree of Water ResourcesEconomy-Society in Beijing-Tianjin-Hebei Region [J]. Yangtze River, 2020, 51(02): 91 96. (in Chinese) 